\title{
Factor V Leiden, Prothrombin and Methylene-tetrahydrofolate reductase genes mutations are associated with recurrent pregnancy losses in Egyptian women
}

\author{
Khaled I. Ghaleb ${ }^{1}$, Aaser M. Abdelazim ${ }^{2 *}$, Haytham A. Ali ${ }^{2}$ \\ ${ }^{1}$ Department of cancer biology, National cancer institute, Cairo University, Cairo, Egypt. \\ ${ }^{2}$ Department of Biochemistry, Faculty of vet. Medicine, Zagazig University, 44511. Zagazig, Egypt
}

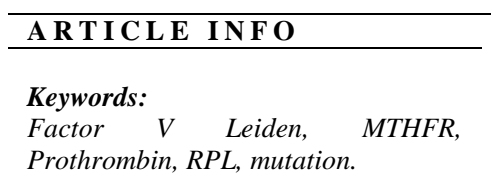

A B S T R A C T
Background: Pregnancies are usually associated with increase
tendency to thrombosis; many cases are associated with inherited
or acquired risks.
Objective: The present study tested the mutations in Factor V
Leiden (FVL) G1691A, prothrombin (PT) G20210A, methylene-
tetrahydrofolate reductase (MTHFR) C677T genes, and their
association with recurrent pregnancy losses in Egyptian women.
Results: The study included 150 subjects of a history of one or
more recurrent pregnancy losses matched with 100 normal
subjects with a history of normal delivery with no complications.
FVL G1691A mutation was detected in (38\%) of patients and in
(5\%) of control. PT G20210A mutation was detected in (6\%) of
patients with no detection in control. MTHFR C677T mutation
was detected in (45.4\%) of patients and in (4\%) of control.
Homozygous with mutant alleles for the three studied mutations
were detected only among patients not control group.
Conclusion: There is a significant association between mutations
of FVL, PT and MTHFR and recurrent pregnancy loss in Egyptian
women.

(C) 2014 Publisher All rights reserved.

\section{INTRODUCTION}

Recurrent pregnancy loss (RPL) is known as the occurrence of two or more spontaneous abortions, affects approximately $5 \%$ of women of reproductive age ${ }^{(\mathbf{1})}$. RPL is a common problem among women in reproductive age. However, relatively few women having one RPL; approximately $5 \%$ of such women experience a second pregnancy loss and only $1-2 \%$ possessed three or more losses ${ }^{(2)}$. Evaluations for RPLs often include detecting parental chromosome abnormalities, identifying maternal exposures, and testing for underlying maternal conditions ${ }^{(3)}$ while in some conditions; surgical interference can be accomplished, such as correcting uterine anomalies and treating with aspirin and heparin ${ }^{(4-6)}$. By the way, many reports have demonstrated the relationships between RPLs and coagulation disorders ${ }^{(7-10)}$. In the time at which a number of studies concerning the relationship between RPLs and thrombophilia have been carried out among several populations around the world ${ }^{(11)}$; this relationship not well studied up till now in Egyptian women. A number of inherited risk factors mutations have been suggested 
to be associated with thrombophilia including FVL G1691A, PT G20210A, and C677T in methylenetetrahydrofolate reductase ${ }^{(12,13)}$. The FVL/ PT variants are the most common genetic variants associated with venous thrombosis $(\mathbf{4}, \mathbf{5})$. About 5-7\% of individuals of northern European white ancestry worldwide are heterogeneously PT mutation carriers ${ }^{(14)}$. PT mutation carriers are also founded in $2.2 \%$ of US non-Hispanic whites and Hispanic/Mexican Americans and in 0.6\% of African Americans (15). The FVL variant is virtually absent in native Asian and African populations, and PT mutation is rare ${ }^{(14,16)}$. On the other hand; MTHFR [EC 1.7.99.5] is considered a key enzyme in the one-carbon metabolism, because it irreversible converts 5, 10methylenetetrahydrofolate to 5methylTHF, which serves as methyl donor for methionine, precursor of SAM. Not only is this pathway important for methyl group synthesis but the lack of methyl group production results in an intracellular accumulation of S-adenosylhomocysteine $(\mathrm{SAH})$, as well as an increase in plasma of total homocysteine levels (tHcy) ${ }^{(17)}$. Great evidence about the association between the homocysteine and venous thrombosis was presented; high plasma homocysteine is positively correlated with venous thrombosis ${ }^{(\mathbf{1 8 - 2 0})}$. In the same line the link between thrombosis and recurrent pregnancy losses was previously studied by Gawish and Al-Khamees, ${ }^{(1)}$ Serrano et al., ${ }^{(7)}$; Hussein et al., ${ }^{(8)}$; Bradey et al., ${ }^{(9)}$. Epidemiological studies showed about 10$12 \%$ of Caucasians of Northern European descent carry the 677TT genotype for MTHFR and have about 25\% higher homocysteine levels than those with the 677CC genotype ${ }^{(21,22)}$. In the present study, we investigated the association between Factor V Leiden, prothrombin and MTHFR genes mutations and adverse pregnancy outcomes among Egyptian women suffering from recurrent miscarriages with unknown etiology compared to control women with uncomplicated pregnancies and deliveries.

\section{MATERIAL AND METHODS}

A. Patients: A case control study was used to evaluate the association between FVL G1691A, PT G20210A, and MTHFR C677T gene mutations and the RPL in Egyptian women. The patients group include one hundred and fifty $(\mathrm{N}=150)$ women with a history of one or more adverse recurrent pregnancy loss were admitted in obstetrics and gynecology department in Kasr El Aini hospital, Cairo University during the period march 2010 April 2012. Subjects were selected in consultation to include only women who are apparent healthy and did not suffer from any complications leading to adverse pregnancy outcome. The Control group include one hundred women $(\mathrm{N}=100)$ with no history of recurrent pregnancy losses, any pregnancy complications, venous thrombosis or other hematological disorders. Matches between patients and control groups were taken in mind; their average age (32 \pm 3 ) years old, marriage age $(22 \pm 3)$ years, with no smoking, no obesity and similar BMI.

B. Sampling protocol: Blood were taken on EDTA from both patients and control groups. The samples were processed to DNA extraction step.

\section{DNA extraction and mutations detection}

DNA extraction, multiplex amplifications with biotinylated primers and reverse hybridization detection method were 
performed according to the kit protocol (Vienna Lab, GmbH, Asturia). 100 ul of whole EDTA blood was incubated with the lysis buffer for 15 minutes, then GenEXTRACT resin was added (it is important that the DNA concentration should not exceed than 20-200 ng/reaction). The amplification was consisted of 15 ul of amplification mix solution, $5 \mathrm{ul}$ of Taq polymerase (Fermentas, Canada Inc., Canada) diluted $0.2 \mathrm{U} / \mathrm{ml}$ by dilution buffer supplied with the kit and 5 ul extracted DNA (40ng/ul). The reaction mix added in $0.2 \mathrm{ml}$ eppendorf tube and incubated in thermal cycler (Applied Biosystem,USA) and denturated at $950 \mathrm{C}$ for 10 minutes followed by 30 cycles (94o $\mathrm{C}$ denaturation, 60o $\mathrm{C}$ annealing and 72o $\mathrm{C}$ for extension) finally at $720 \mathrm{C}$ for 10 minutes. Amplicons was checked via gel electrophoresis. A strip assay protocol was started by incubation of $10 \mathrm{ul}$ of amplicons with $10 \mathrm{ul}$ of denaturation solution for 15 minutes, followed by hybridization with strip probes in tracks with hybridization buffer and adjusted hybridization temperature must be $45 \pm 50 \mathrm{C}$ for 45 minutes in shaking water bath profiBlot device (Tecan, Switzerland) for hybridization. Results were easily interpreted visually; there is no need for any documentation system. A positive reaction of the control indicated the correct function of the conjugate solution and color Developer.

\section{Statistical analysis}

The data was processed using the statistical package for social science (SPSS Inc., Version 18, Chicago, Illinois, USA). Chi-Square was used to compare parameters.

\section{RESULTS}

Factor V Leiden G1691A mutation: the mutation is detected in (38\%) of patients (6\% and 32\%) with homozygous and heterozygous mutations respectively; While heterogeneous mutation is detected in $(5 \%)$ of control with no detection of homogenous mutations in control tables 1 , 2 at $(P \leq 0.05)$.

Prothrombin G20210A mutation: the mutation is detected in $(6 \%)$ of patients (2\%\& 4\%) with homogenous and heterogeneous mutations respectively; while there is no detection of the mutation in control group at all tables 1,3 at $(P \leq$ $0.05)$.

Methyelenetetrahydrofolate reductase C677T mutation: the mutation is detected in $(45.3 \%)$ of patients with $(7.3 \% \& 38 \%)$ homogenous and heterogeneous mutation respectively; while heterogeneous mutation is detected in (4\%) of control with no detection of homogonous mutation in control tables 1,4 at $(P \leq 0.05)$.

\section{DISCUSSION}

RPL is associated with multi-factorial risks; genetic risk factors represent the major cause of such condition with a cooperation of other acquired factors ${ }^{(\mathbf{1 2})}$. Thrombosis as a condition of increased tendency of clot formation is considered one of the risk factors which contribute to recurrent abortion (23). According to Egyptian population there are no provided records about the actual incidence of RPLs. The cause may be due to the lack of published data in this subject. Recent studies demonstrated the association between RPL and genetic mutations of thrombophilic factors in different populations $(\mathbf{2 4}, \mathbf{2 5})$. To the best of our knowledge we are the first authors who are 
recording the association between thrombosis and RPL in Egyptian population. In the present study we investigate the association of FVL G1691A, PT G20210A, and MTHFR C677T gene mutations and RPL in Egyptian women. There is an important need for such study; firstly is to examine these mutations in Egyptian population due to the fact that the incidence of the mutation in different populations is affected by racial and ethnic differences in the gene frequency ${ }^{(26)}$. Secondly; to solve the problem of evident publication bias, a reporting a lack of association between genetic thrombophilia and the number of peer reviewed papers reporting an association ${ }^{(1,27)}$. FVL firstly described as the most prevalent genetic risk factor for thrombosis in human in $1994{ }^{(28)}$, association between FVL and RPL in human is proved by many authors $(\mathbf{8}, \mathbf{9}, \mathbf{1 2}$, 24). The present study demonstrates that FVL mutation (G1691A) is correlated with recurrent abortion in Egyptian population. The heterozygous mutation was detected with significantly higher frequency among patients $(32 \%)$ in comparison to the control group (5\%), with the homozygous mutant haplotype only detected among patients. These results are in agreement with earlier reports of $(\mathbf{1 , 8 , 2 9 , 3 0 )}$ recorded high prevalence of FVL mutation among cases with abortions. In the same line of our study; Hussein et al., ${ }^{(8)}$ recorded no homozygous mutation in the healthy population; while there are $5.6 \%$ of healthy subjects are G1691A heterozygous. Related to our study; $5 \%$ of control shows heterozygous FVL G1961A mutation. The way by which FVL mutation is implicated in RPL is due to induction of a hypercoagulable state, which increases the risk of venous thrombosis seven-fold among heterozygous carriers and about eightyfold among homozygous carriers compared to non-carriers (31). So thrombosis of the placental vessels is assumed to be an important factor in fetal loss ${ }^{(24)}$. On the contrary, some reports failed to find a significant association between FVL G1691A mutation and PRLs (32-34). It well known that PT G20210A gene mutation resulted in high PT levels the condition which leads to thombophilia (35). The problem of PT mutation and RPLs in case-control subjects was described in the present study and previous reports of (36-38) also Bradley et al., ${ }^{\text {(7) }}$ supported an association between PT mutation carries and the status of RPL. However important gaps in knowledge remain. From this point of view, we evaluated the PT G20210A mutation. Our data shows that the homozygous and heterozygous G20210A mutations were detected only in the patients by $(2 \%)$ and (4\%) respectively, while there is no detection of the previous mutations in the control group. Although it comes on contrary of the report of Coppens ${ }^{(39)}$, this proves the association between PT G20210A mutation and the RPL, which came in agreement with reports of Bradly et al., (7), Finan et al., ${ }^{(12)}$, Brenner, (40), Grandone, (41), Glueck, ${ }^{(42)}$, Souza, ${ }^{(43)}$. MTHFR C677T gene missense mutation encodes for a thermolabile variant with reduced enzymatic activity (44); the condition, which resulted in accumulation and elevation of plasma homocysteine ${ }^{(45)}$. High plasma homocysteine is implicated in venous thrombosis (46). However, it was not ascertain whether the high homocysteine level cause thrombosis or was a 
consequence of it ${ }^{(19)}$. Studies of genetic variants of MTHFR associated with high homocysteine level might prove the link of high homocysteine level and the incidence of venous thrombosis ${ }^{(18)}$. Previously, there is strong evidence on the implication of MTHFR mutation in the occurrence of venous thrombosis (11, 13 and 19). As it implicated in thrombosis for this reason; many reports involve MTHFR C677T mutation as a causal agent of RPLs due to thrombosis of utroplacental vasculture ${ }^{(7,}$ 10). Our results prove this association as homogenous and heterogamous C677T mutation was detected in $11.7 \%$ and $38 \%$ in subjects with RPLs respectively with total detection of the mutation by $54.6 \%$

\section{REFERENCES}

1. Gawish, G., E., and O., Al-Khamees, 2013: Molecular Characterization of Factor V Leiden G1691A and Prothrombin G20210A Mutations in Saudi Females with Recurrent Pregnancy Loss; J Blood Disorders Transf 4:6

2. Christiansen, O. B., R., Steffensen, H. S., Nielsen, K., Varming 2008. Multifactorial etiology of recurrent miscarriage and its scientific and clinical implications. Gynecol Obstet Invest. 66:257-267.

3. Warren, J. E. 2008. Silver RM. Genetics of pregnancy loss. Clin Obstet Gynecol. 51:84-95.

4. Kujovich, J. L. 2005. Factor V Leiden thrombophilia.

GENEReviews. http://www. ncbi.nlm.nih.gov/bookshelf/br.fcgi?bo ok_gene\&part_factor-v-leiden. .

5. Kujovich, J. L. 2009. Prothrombin thrombophilia. GENEReviews. http://www.ncbi. in patients if compared with control subjects (4\%) only. In conclusion; there is a significant association between FVL G1691A, PT G20210A and MTHFR C677T gene mutations and poor pregnancy outcome in the Egyptian population.

\section{Acknowledgment}

Authors thank the Kasr El-Aini hospital department of obstetrics and gynecology consultant team for their effort in preparation of experimental subjects and performing medical examinations for all patients and control.

nlm.nih.gov/bookshelf/br.fcgi?book_g ene\&part_ptt.

6. Empson, M., M., Lassere, J., Craig, J., Scott. 2005. Prevention of recurrent miscarriage for women with antiphospholipid antibody or lupus anticoagulant. Cochrane Database Syst Rev:CD002859.

7. Bradley L.A., G. E., Palomaki, J., Bienstock, Varga and A., Joan. 2012. Scott JA. Can Factor V Leiden and prothrombin G20210A testing in women with recurrent pregnancy loss result in improved pregnancy outcomes?: Results from a targeted evidence-based review. Genetics in medicine. 14: 39-50.

8. Hussein A. S., D., Hisham, S., Khaled. 2012. Association between factor V Leiden mutation and poor pregnancy outcomes among Palestinian women. Thrombosis Research; 126:78-82.

9. Serrano F, Lima ML, Lopes C, Almeida JP, Branco J. 2011. Factor V Leiden and prothrombin G20210A in Portuguese women with recurrent 
miscarriage: is it worthwhile to investigate? Arch Gynecol Obstet. 284(5):1127-32

10. Rai R, Tuddenham E, Backos M, Jivraj S, El'Gaddal S, et al. (2003) Thromboelastography, whole-blood haemostasis and recurrent miscarriage. Hum Reprod. 18: 2540-2543.

11. Alfirevic Z, Roberts D, Martlew V. 2002. How strong is the association between maternal thrombophilia and adverse pregnancy outcome? A systematic review. Eur J Obstet Gynecol Reprod Biol. 101(1):6-14.

12. Finan R, Tamim H, Ameen G, et al. 2002. Prevalence of FactorVG1691A (factorV-Leiden) and Prothrombin gene mutations in a recurrent miscarriage population. Am $\mathbf{J}$ Hematol; 71:300-5.

13. Isotalo PA, Wells GA, Donnelly JG. 2000. Neonatal and fetal methylenetetrahydrofolate reductase genetic polymorphisms: an examination of C677T and A1298C mutations. Am J Hum Genet. 67(4):986-90.

14. Rees DC, Cox M, Clegg JB. 1995. World distribution of factor $\mathrm{V}$ Leiden. Lancet. 346:1133-1134.

15. Chang MH, Lindegren ML, Butler MA, et al. 2009. Prevalence in the United States of selected candidate gene variants: Third National Health and Nutrition Examination Survey, 1991-1994. Am J Epidemiol. 169:54 66.

16. Lucotte G, Mercier G. 2001. Population genetics of factor $\mathrm{V}$ Leiden in Europe. Blood Cells Mol Dis; 27:362-367.

17. Selhub, J. Annu. Rev. Nutr. (1999) ; 19, 217-246.
18. Davey Smith G, Ebrahim S. 2003. Mendelian randomization: can genetic epidemiology contribute to understanding environmental determinants of disease? Int $\mathrm{J}$ Epidemiol. 32: 1-22.

19. Den Heijer M., Lewington S. and Clarke R. 2005. Homocysteine, MTHFR and risk of venous thrombosis: a meta-analysis of published epidemiological studies. $\mathbf{J}$ Thromb Haemost. 3: 292-9.

20. Blickstein I (2006). Thrombophilia and women's health: An overview. Obstet Gynecol Clin North Am 33: 347-356.

21. Jacques PF, Bostom AG, Williams RR, Ellison RC, Eckfeldt JH, Rosenberg IH, Selhub J, Rosen R. 1996. Relation between folate status, a common mutation between methylenetetrahydrofolate reductase, and plasma homocysteine concentrations. Circulation. 93: 7-9.

22. Hustad S, Ueland PM, Vollset SE, Zhang Y, Bjorke-Monsen AL, Schneede J. 2000. Riboflavin as a determinant of plasma total homocysteine: effect modification by methylenetetrahydrofolate reductase C677T polymorphism. J Clin Chem; 46: 1065-71.

23. Cooper DN. 1994.The molecular genetics of familial venous thrombosis. Baillières Clin Haematol; 7:637-74.

24. Van Dunne F.M., Doggen C.J.M., Heemskerk M., Rosendaal F.R., Helmerhorst F.M. 2005. Factor V Leiden Mutation in Relation to Fecundity and Miscarriage in $\mathrm{W}$ omen with Venous Thrombosis. Hum Reprod. Mar; 20(3): 802-6. 
25. Visser J, Ulander V; Frans M. Helmerhorst1; Katja Lampinen3; Laure Morin-Papunen4; Kitty W. M. Bloemenkamp1; Risto J. Kaaja2. Thromboprophylaxis for recurrent miscarriage in women with or without thrombophilia. Thromb Haemost 2011; 105: 295-301.

26. Burchard EG, Ziv E, Coyle N, Gomez SL, tang H, Karter AJ, et al. 2003. The importance of race and ethnic background in biomedical research andclinical practice. $\mathrm{N}$ Eng $\mathrm{J}$ med; 348.

27. Carp H, Torchinsky A, Fein A, Toder V (2001) Hormones, cytokines and fetal anomalies in habitual abortion. Gynecol Endocrinol 15: 472-483

28. Bertina RM, Koeleman BP, Koster T, Rosendaal FR, Dirven RJ, de Ronde $\mathrm{H}$, van der Velden PA, Reitsma PH (1994) Mutation in blood coagulation factor $\mathrm{V}$ associated with resistance to activated protein C. Nature ;369(6475):64-67

29. Hopmeier P, Puehringer H, van Trotsenburg M, Atamaniuk J, Oberkanins C, Dossenbach-Glaninger A. 2008. Association of endothelial protein $\mathrm{C}$ receptor haplotypes, factor $\mathrm{V}$ Leiden and recurrent first trimester pregnancy loss. Clin Biochem; 41 (12):1022-4.

30. Zammiti W, Mtiraoui N,Mercier E, Abboud N, Saidi S,Mahjoup T, et al. 2006. Association of factor $F$ gene polymorphisms (Leiden; Cambridge; Hong Kong and HR2 haplotype) with recurrent idiopathic pregnancy loss in Tunisia. A case control study. Thromb Haemost; 95(4):612 7.

31. Rosendaal F.R., Koster T., Vandenbroucke J.P., Reitsma P.H.
1995. High risk of thrombosis in patients homozygous for factor $\mathrm{V}$ Leiden (activated protein $\mathrm{C}$ resistance). Blood,; 85; 6: 1504- 1508.

32. Altintas A, Pasa S, Akdeniz N, Cil T, Yurt M, Ayyildiz O, et al. 2007. Factor V Leiden and G20210A prothrombin mutations in patients with recurrent pregnancy loss: data from the southeast of Turkey. Ann Hematol; 86(10):727-31.

33. Howard C, Ophira S, Daniel S, Rim D, Nurith R, Aida I. 2002. Prevalence of genetic markers for thrombophilia in recurrent pregnancy loss. Hum Reprod; 6:1633-7.

34. Pauer HU, Voigt-Tschirschwitz T, Hinney B, Burfeind P, Wolf C, Emons $\mathrm{G}$, et al. 2003. Analyzes of three common thrombophilic gene mutations in German women with recurrent abortions. Acta Obst Gynecol Scand; 82:942-7.

35. Poort SR, Rosendaal FR, Reitsma PH, Bertina RM. 1996. A common genetic variation in the 3_-untranslated region of the prothrombin gene is associated with elevated plasma prothrombin levels and an increase in venous thrombosis. Blood; 88:3698-3703.

36. Kovalevsky G, Gracia CR, Berlin JA, Sammel MD, Barnhart KT. 2004. Evaluation of the association between hereditary thrombophilias and recurrent pregnancy loss: a metaanalysis. Arch Intern Med; 164:558563.

37. Robertson $\mathrm{L}, \mathrm{Wu} \mathrm{O}$, Langhorne $\mathrm{P}$, et al. 2006. Thrombosis: Risk and Economic Assessment of Thrombophilia Screening (TREATS) Study. Thrombophilia in pregnancy: a 
systematic review. $\mathrm{Br} \mathrm{J}$ Haematol; 132:171-196.

38. Kist WJ, Janssen NG, Kalk JJ, Hague WM, Dekker GA, de Vries JI. 2008. Thrombophilias and adverse pregnancy outcome - A confounded problem! Thromb Haemost; 99:77-85.

39. Coppens M, Folkeringa N, Teune MJ, Hamulya'k K, van der Meer J, Prins $\mathrm{MH}$, Bu“ller HR, Middeldorp S (2007). Outcome of the subsequent pregnancy after a first loss in women with the factor $\mathrm{V}$ Leiden or prothrombin 20210A mutations. J Thromb Haemost 5(7):1444-1448.

40. Brenner B, Sarig G, Weiner Z, Younis J, Blumenfeld Z, Lanir N. 1999. Thrombophilic polymorphisms are common in women with fetal loss without apparent cause. Thromb Haemost; 82:69.

41. Grandone E, Margaglione M, Colaizzo D, d'Addedda M, Cappucci G, Vecchione G, Scianname N, Pavone G, Di Minno G. 1997. Factor $\mathrm{V}$ Leiden is associated with repeated and recurrent unexplained fetal losses. Thromb Haemost; 77:822-824.

42. Glueck CJ, Gogenini S, Munjal J, Tracy T, Pranikoff J, Wang P. 2008. Factor V Leiden mutation: a treatable etiology for sporadic and recurrent pregnancy loss. Fertil Steril; 89:410416
43. Souza SS, Ferriani RA, Pontes AG, Zago MA, Franco RF. 1999. Factor V Leiden and factor II G20210A mutations in patients with recurrent abortion. Hum Reprod. 14:24482450.

44. Frosst, P., Blom H. J., Milos, R., Goyette, P., Sheppard, C. A., Matthews, R. G., Boers, G. J. H., denHeijer, M., Kluijtmans, L. A. J., van den Heuvel, L. P. \& Rozen, R. Nat. Genet. 1995; 10, 111-113.

45. Den Heijer M, Ingeborg A. Brouwer, Gerard M. J. Bos, Henk J. Blom, Nathalie M. J. van der Put, Anja P. Spaans, Frits R. Rosendaal, Chris M. G. Thomas, Hans L. Haak, Pierre W. Wijermans and Wim B. J. Gerrits. 1998. Vitamin Supplementation Reduces Blood Homocysteine Levels: A Controlled Trial in Patients With Venous Thrombosis and Healthy Volunteers. Arterioscler Thromb Vasc Biol.;18:356-361

46. Anderson FA, Spencer FA. 2003. Risk factors for venous thromboembolism. Circulation; 107 (Suppl. I): I-9-I-16. 
Table (1): Incidence of the gene mutations in patients and control groups

\begin{tabular}{lcccc}
\hline & Groups & Homozygous & Heterozygous & Negative \\
\hline Factor V & Patient & $9(6 \%)$ & $48(32 \%)$ & $93(62 \%)$ \\
Leiden & Control & $0(0 \%)$ & $5(5 \%)$ & $95(95 \%)$ \\
& Patients & $3(2 \%)$ & $6(4 \%)$ & $141(94 \%)$
\end{tabular}

Prothrombin

\begin{tabular}{|c|}
\hline Control \\
\hline
\end{tabular}

MTHFR

$\begin{array}{lccc}\text { Patients } & 11(7.3 \%) & 57(38 \%) & 82 \\ \text { Control } & 0(0 \%) & 4(4 \%) & 96(96 \%)\end{array}$

Table (2): Factor V Leiden G1691A mutation in patients and control groups.

\begin{tabular}{lcccc}
\hline $\begin{array}{l}\text { FV Leiden } \\
\text { G1691A }\end{array}$ & Patients & Control & $\begin{array}{c}\text { P } \\
\text { value }\end{array}$ & CI \\
\hline Positive & $57(38 \%)$ & $5(5 \%)$ & $\leq 0.05$ & \\
Negative & $93(62 \%)$ & $95(95 \%)$ & $\geq 0.05$ & \\
\hline
\end{tabular}

Table (3): Prothrombin G20210A mutation in patients and control groups.

\begin{tabular}{lcccc}
\hline $\begin{array}{l}\text { Prothrombin } \\
\text { G20210A }\end{array}$ & Patients & Control & $\begin{array}{c}\text { P } \\
\text { value }\end{array}$ & CI \\
\hline Positive & $9(6 \%)$ & $0(0 \%)$ & $\leq 0.05$ & \\
Negative & $141(94 \%)$ & $100(100 \%)$ & $\geq 0.05$ &
\end{tabular}

Table (4): Methylenetetrahydrofolate reductase C677T mutation in patients and control groups.

\begin{tabular}{lcccc}
\hline MTHFR C677T & Patients & Control & $\begin{array}{c}\text { P } \\
\text { value }\end{array}$ & CI \\
\hline Positive & $68(45.3 \%)$ & $4(4 \%)$ & $\leq 0.05$ & \\
Negative & $82(54.7 \%)$ & $96(96 \%)$ & $\geq 0.05$ & \\
\hline
\end{tabular}

